\title{
Complutum
}

ISSN: 1131-6993

\section{Identidad y tecnología cerámica: el trabajo alfarero en Luxor (Egipto)}

Juan Jesús Padilla Fernández ${ }^{1}$

Recibido: 15 de octubre de 2016 / Aceptado: 10 de marzo de 2017

Resumen. El artículo que aquí se presenta tiene la intención de mostrar los datos de cuatro campañas de investigación etnoarqueológica realizadas por el proyecto arqueológico español "Thutmosis III Temple Project", centradas en estudiar los trabajos alfareros de Luxor y su región circundante. El desarrollo de un análisis focalizado desde perspectivas técnicas, ha permitido entender la complejidad social que actualmente subyace dentro de lo que se denomina oficialmente como comunidad egipcia, al mismo tiempo que ha reforzado la visión de la cerámica como un contenedor cargado de significado social y simbólico.

Palabras clave: Etnoarqueología; cerámica; artesanos; religión; estatus; poder.

\section{[en] Identity and Ceramic Technology: the Pottery Craftsmanship in Luxor (Egypt)}

Abstract. This paper aims to present the data obtained by the Spanish archaeological project "Thutmosis III Temple Project" during four ethnoarchaeological research seasons devoted to the study of potter workshops from Luxor and its surrounding areas. An analysis focused on technical perspectives was developed, which ultimately allowed to understand the social complexity that currently lies within what is officially labelled as Egyptian community, while reinforcing the view of ceramics as containers full of social and symbolical meaning.

Keywords: Ethnoarchaeology; Pottery; Craftsmen; Religion; Status; Power.

Sumario. 1. Introducción. 2. Luxor: Tierra de alfareros milenarios. 3. Producción alfarera e identidad religiosa. 4. Producción alfarera e identidad social.

Cómo citar: Padilla Fernández, J.J. (2017): Identidad y tecnología cerámica: el trabajo alfarero en Luxor (Egipto). Complutum, 28(2): 379-398.

\section{Introducción}

¿En Egipto sólo encontramos pirámides? Las visitas contratadas por tour operadores parecen demostrar que el país que gira en torno al Nilo, únicamente se encuentra repleto de sarcófagos, utensilios elaborados con metales preciosos, esculturas ciclópeas o estelas repletas de jeroglíficos. Pero, ¿qué ocurre con todo lo demás? Como es lógico suponer, en Egipto no es oro todo lo que reluce, siendo de facto la materialidad cerámica el elemento más común desde un punto de vista arqueológico, acaparando de forma mayoritaria la totalidad del registro. Los "cacharros" no venden y por ello disponen de un protagonismo académico escaso. No obstante, ya existen equipos que centran una atención relevante en los objetos concebidos en barro, entre los que cabe destacar el dirigido por la Dra. Myriam Seco Álvarez, ubicado al pie de la montaña tebana, y centrado en la excavación y restauración del famoso

\footnotetext{
Esta investigación ha sido posible gracias al proyecto español de excavación, restauración y musealización del Templo de Millones de Años de Tutmosis III en Luxor (Egipto), y bajo el soporte económico de la Fundación Botín, Santander Universidades, Cemex, la Fundación Cajasol y la Universidad de Granada.

2 FPU-MED. Departamento de Prehistoria. Facultad de Geografía e Historia. Departamento de Prehistoria (España)

E-mail: juanjpad@ucm.es
} 
templo funerario de Tutmosis III. Huyendo de viejos convencionalismos y haciendo hincapié en la obligatoriedad de interpretar secuencias estratigráficas atestadas de elementos cerámicos de variada índole, este colectivo científico español ha puesto en marcha líneas de trabajo destinadas no sólo a generar secuencias cronotipológicas, sino a descubrir el por qué social de la fabricación y disposición de estos productos cerámicos en las inmediaciones de un recinto dedicado a los ritos sagrados. Además, el hecho de que la egiptología tradicional haya tendido a obviar a menudo lo concerniente directamente con las personas, animó a este equipo multidisciplinar a plantear la realización de estudios etnoarqueológicos destinados a examinar las poblaciones alfareras que todavía siguen viviendo en las inmediaciones de Luxor, la antigua Tebas.

Precisamente, el texto que estas líneas introducen se configura como el resultado de cuatro campañas de exploración desarrolladas en paralelo a los trabajos realizados en el templo funerario, entre los años 2011 y 2014, y cuyo objetivo principal era el de intentar valorar el papel significativo que la cultura material juega para el entendimiento de determinados mecanismos sociales. En nuestro caso, la cerámica se convierte en un reflejo fiel de los aspectos de vida propios de los grupos humanos que la elaboran y consumen (Gosselain 2011a). Tomando como condición obligada el no incidir únicamente en lo perceptible a simple vista, sino en la necesidad de rastrear también en el gesto técnico, la aplicación del concepto de cadena técnico operativa (Lemonnier 1993) ha dejado al descubierto el uso social que se hace de los conjuntos cerámicos como elementos culturales y reforzadores de identidad. La indagación sistemática en su modo de trabajar, ha ayudado a discernir maneras diferentes de hacer y utilizar cerámica. En este contexto, principalmente la variabilidad religiosa y en segundo orden el tipo de material fabricado, condicionan el establecimiento de producciones alfareras singulares en las que parece no haber una clara homogeneidad de prácticas.

\section{Luxor: Tierra de alfareros milenarios}

Muchas son las representaciones iconográficas que escenifican la importancia del oficio alfarero en el antiguo Egipto (Arnold y Bourriau 1993). No obstante, pocos son los trabajos
(Bourriau et al. 2000; Jamieson y Warfe 2005; Doherty 2015) que abordan con precisión los menesteres de éste. Si nos ceñimos al campo de las investigaciones etnoarqueológicas realizadas en este marco geográfico, podemos decir que el escenario sería parecido, identificándose exclusivamente un número pequeño de publicaciones que profundizan poco en cuestiones de índole social (Brissaud 1982; Nicholson y Patterson 1991; Nicholson 1995; Redmount 2000; Duistermaat y Groot 2008). Básicamente, son aproximaciones que buscan resaltar a grandes rasgos la continuidad existente entre el Egipto faraónico y las comunidades rurales que continúan poblando las orillas del Nilo (Wendrich 2013). Hasta ahora, la disciplina etnoarqueológica ha sido aplicada como una teoría procesualista de alcance medio, con el fin de "globalizar el pasado" (Hernando 2006: 26) a través del rastreo de analogías directas que ayuden a explicar y completar genéricamente lo atestiguado en bajo relieves o grupos escultóricos milenarios. Así mismo, en ellos se produce un énfasis exacerbado por el cómo, contribuyendo a que los estudios de índole etnoarqueológica queden exclusivamente reducidos a la observación en sí de un determinado proceso productivo, instituyéndose éste, como el fin máximo a lograr (González-Ruibal 2003).

En nuestro caso, y con el objetivo de alcanzar dimensiones sociales relacionadas con cuestiones que atañen al para qué y al por qué de los recipientes cerámicos, planteamos la ejecución de otro concepto de etnoarqueología, basado en el vínculo efectivo de sociedad y cultura material (García Rosselló 2008). Una perspectiva que aspira igualmente a concienciar sobre la diversidad y multiplicidad de conexiones habidas entre las personas y sus herramientas (González-Ruibal 2005; Lemonnier 2012). La etnoarqueología, tomando como punto de partida la consideración antropológica del objeto, se convierte en una estrategia esencial para concebir inferencias acerca del sentido de las cosas en cada comunidad humana, independientemente de que ésta sea presente o pasada (David y Kramer 2001).

Etnográficamente hablando, Egipto continúa manteniendo una fuerte vinculación con la artesanía cerámica. Si bien, debemos destacar que los procesos y técnicas productivas de hoy son radicalmente opuestos a los evidenciados milenios atrás (Doherty 2015). La elaboración de la denominada como "vajilla egipcia" (Redmount 2003: 154), el conjunto de elementos 

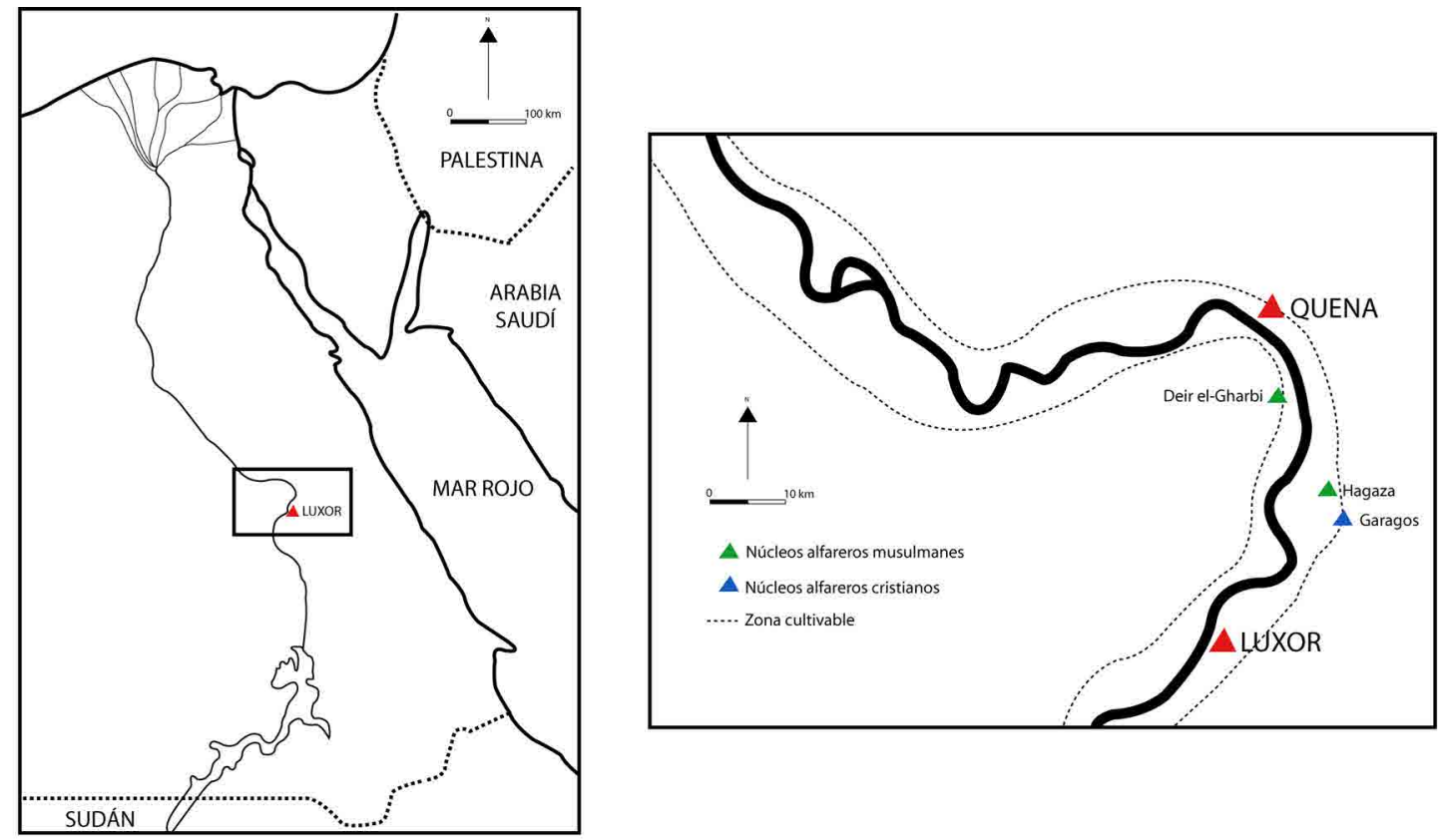

Figura 1. Disposición exacta de los núcleos alfareros musulmanes y cristiano-coptos asentados en la región de Luxor.

cerámicos considerados como indispensables en el transcurso de la vida diaria, se distribuye actualmente por la totalidad del territorio de forma regular, agrupándose especialmente en ambientes en los que el acopio de recursos hídricos es más sencillo. De forma concreta podemos distinguir siete grandes áreas: los suburbios circundantes a la ciudad de Cairo, Siwa, El Fayum, el entorno de Amarna, Dahla, Luxor y la región de Asuán (Cooper 2000; Calvo Trias y García Rosselló 2012).

El entorno que aquí nos ocupa, queda integrado entre las gobernaciones administrativas de Quena y Luxor (Fig. 1). En una superficie aproximada de $9500 \mathrm{~km}^{2}$, alrededor de 50 talleres alfareros trabajan diariamente para abastecer la todavía fuerte demanda cerámica de una sociedad preindustrial que cuenta con más de tres millones de habitantes. Las investigaciones se centraron en tres núcleos poblacionales, por ser éstos los que albergaban ciertamente una mayor concentración. El primero de ellos se emplaza cerca del asentamiento predinástico de Nagada, en la rivera este, y recibe el nombre de Deir El-Gharbi. Los 22 alfares documentados se encargan preferentemente de la confección de ánforas de agua y tinajas, llegando a alcanzar cada uno la producción de
1000 piezas mensuales. En el margen oeste, en cambio, la localidad de Hagaza alberga 33 obradores que crean tipos destinados a la cocción y preparación de alimentos, estimándose la realización de 400 piezas diarias por cada uno de éstos. El tercer núcleo importante es Garagos, un pequeño reducto cristiano-copto a tan solo 10 kilómetros de Hagaza, que manufactura en elevadas cantidades la práctica totalidad de variantes formales del ajuar doméstico cerámico.

En términos generales la cerámica producida en Luxor se caracteriza por haber sido modelada a torno, ostentar decoraciones naturalistas y geométricas y, sólo en los casos que corresponda, disponer a nivel superficial de un vidriado cromático de naturaleza plúmbica. Aparentemente, parece que a partir de la consecución de cinco fases generales los maestros alfareros fabrican una cerámica más o menos similar, con la misión idéntica de obtener recipientes funcionales y de uso cotidiano. Sin embargo, el análisis pormenorizado de las secuencias de manufactura, distribución y consumo, denota cambios substanciales que otorgan a las producciones cerámicas un carácter individualizado y acorde a colectividades específicas. 
En el tránsito de casi seis meses de investigación, si juntamos el tiempo de cada una de las campañas realizadas, planificamos una hoja de ruta basada en la toma de la mayor cantidad de datos etnoarqueológicos posible. A través de una observación participante, postura que concede al investigador la capacidad de interactuar y apreciar de cerca las actividades de un grupo sin ser parte constituyente de la esencia del mismo (Kawulich 2005), entablamos una relación directa con 40 complejos alfareros, 36 musulmanes y 4 cristianos coptos, con la finalidad de indagar exhaustivamente en sus procesos tecnológicos y variaciones. Dada la imposibilidad temporal de hacer frente al estudio completo de todos los alfares de signo musulmán, decidimos hacer una elección cuantitativa en función del tipo de material cerámico realizado. En cambio y debido principalmente a su número reducido, si fueron analizados todos aquellos que se correspondían con el ámbito cristiano. Con la ayuda excepcional de Sayed Alí, nuestro traductor árabe-español local, también fue factible el uso cualitativo de entrevistas semi-estructuradas (un total de 120) que ayudaron a dilucidar el por qué y el significado de las elecciones tecnológicas tomadas según en qué momento y casos. Llevadas a cabo tanto a productores como a consumidores ${ }^{3}$, éstas incluían desde preguntas básicas, tales como las que se circunscribían a tratar de entender las particularidades advertidas en las acciones y gestos técnicos de las cadenas operativas de producción, hasta cuestiones relacionadas con el valor religioso intrínseco en los propios recipientes, la segregación de género en el aprendizaje y posterior dominio del oficio alfarero, la graduación e importancia social de los tipos cerámicos en base a su funcionalidad y la jerarquización inter-artesanal (Tabla 1). La selección, cotejo y comparación de todas las respuestas recibidas, así como su contrastación con la información recogida in situ y visualmente en los escenarios estudiados, nos conduce a ratificar que la cerámica transmite sin la necesidad de hablar determinadas maneras de vivir (Lemonnier e. p.).

\section{Producción alfarera e identidad religiosa}

Cuando a un alfarero musulmán o cristianocopto se le pregunta por quién es, ambos responden autodenominándose de igual modo "100\% Egyptians", un concepto muy occiden- tal que los identifica a todos ellos simplemente como egipcios, sin variabilidad alguna. Por intereses exclusivamente políticos y por miedo al estallido de un conflicto religioso que altere la frágil coexistencia pacífica del país, el Estado egipcio lleva más de 50 años trabajando en un concepto identitario de nación o Patria. El deseo de estructurar desde la homogeneidad, ha propiciado la construcción y admisión de una identidad política a secas, basada en una bandera, un himno y un marco territorial limitado por una frontera. Como producto de una “economía de poder" (González-Ruibal 2011), el ser egipcio o no, se ha institucionalizado como un gentilicio étnico que expresa una identidad común. Pero, ¿qué sucede realmente cuando salimos de la versión oficial? Lógicamente podemos entrever que la materialidad no coincide en absoluto con lo transmitido a nivel gubernamental.

El desgranamiento de las cadenas técnicas operativas cerámicas desplegadas por las comunidades musulmanas y cristianas-coptas de Hagaza, Deir el-Gharbi y Garagos, intuye modificaciones importantes y asiente la presencia de pautas de grupo únicas, relacionadas sobre todo con percepciones distintas de entender el mundo (Fig. 2). A pesar de llevar a la práctica las mismas cinco fases para crear piezas de naturaleza cerámica, éstas se muestran repletas de condicionantes simbólicos. Y es que la técnica se forja como una parte primordial de la cultura (Dietler y Herbich 1998).

Ya desde el inicio, en los procesos de selección $\mathrm{y}$ aprovisionamiento de las materias primas intuimos una clara diferenciación en el modo de actuar de los alfareros cristianos-coptos de Garagos y los musulmanes de Hagaza. Los primeros no se encargan de la recolección. Por cuestiones religiosas deciden transportar arcilla desde una cantera ubicada en Asuán, a más de $250 \mathrm{~km}$ de distancia. El hecho de estar bendecida por el obispo de Asuán, una figura muy respetada dentro de la Iglesia Ortodoxa Copta, les condiciona a despreciar en sentido literal aquella que puede conseguirse con facilidad en el marco geográfico que les rodea. Un comportamiento que sin duda rompe con el criterio de lo material, pero que puede ser más común de lo que parece (Michelaki et al. 2014; Albero 2016). En cambio, los alfareros musulmanes de Hagaza y Deir el-Gharbi acopian todas sus necesidades en entornos cercanos, acciones que concuerdan perfectamente con el concepto de Site Catchment Analisys propues- 


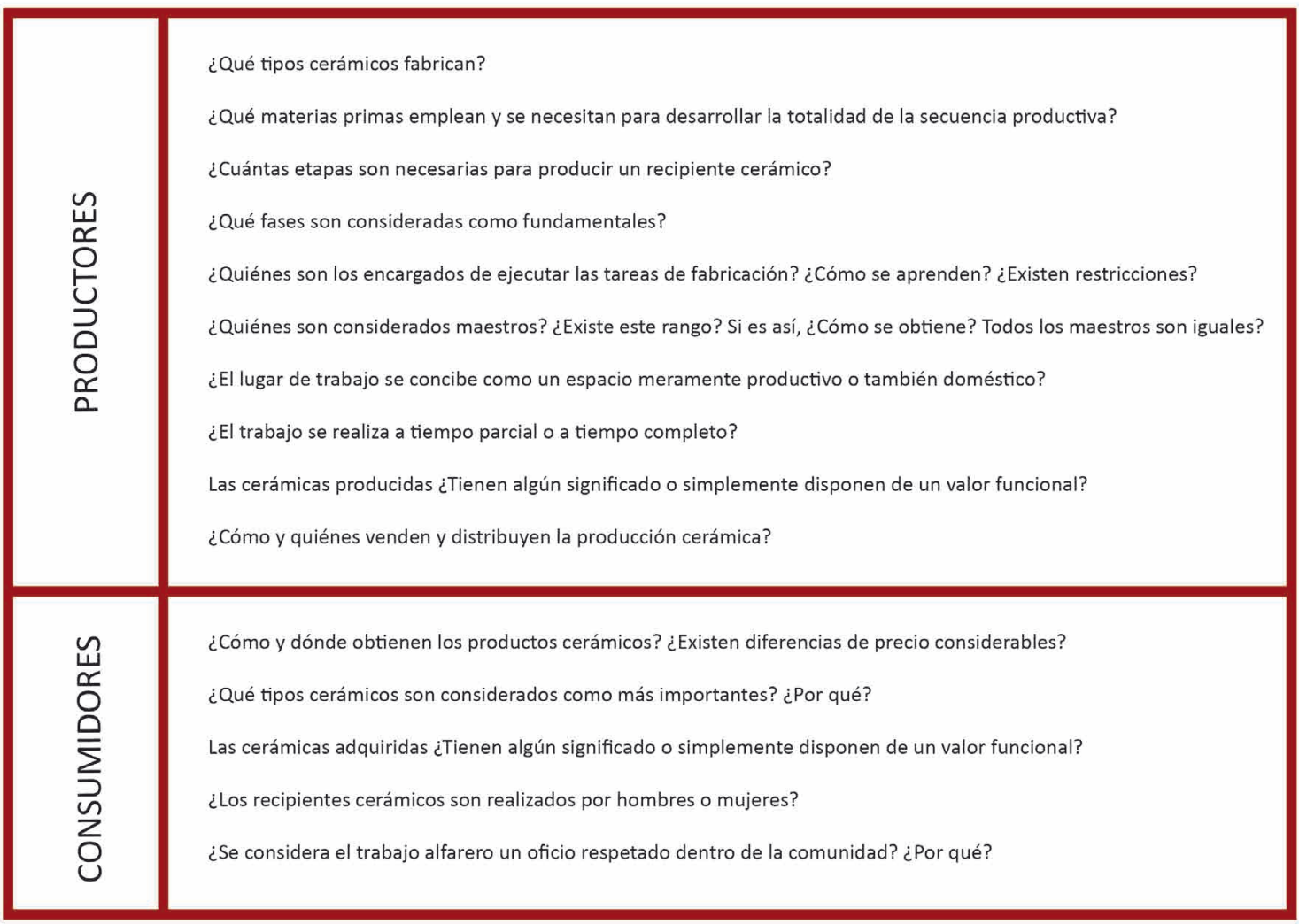

Tabla 1. Relación de preguntas formuladas tanto a productores como a consumidores en las entrevistas concertadas. Al margen de tales cuestiones fueron apuntados también los nombres y datos correspondientes al sexo, edad y signo religioso.

to por Arnold (2006), al obviar sistemáticamente los recursos localizados en un diámetro mayor a los ocho kilómetros a la redonda.

A continuación y tras el transporte del mineral de arcilla, bien por medio de tracción animal o mecánica, se procede a su depuración y decantación. En ésta también es factible apreciar con claridad métodos contrapuestos. Tanto los alfareros de Hagaza como Deir elGharbi disponen de balsas, a veces excavadas en la superficie y otras construidas a través de muretes de piedra, que utilizan para disolver en agua los bloques de arcilla extraídos y consumar el añadido de desgrasantes. Las impurezas de mayor volumen se eliminan mediante un expurgo manual, quedando depositadas las más pequeñas en el fondo como consecuencia de la acción de levigado. Seguidamente y justo después de que el sol realice su acción y evapore el agua sobrante, la arcilla convertida en barro es extraída de las capas superiores de las piletas, desechando las inferiores. Los alfareros de Garagos, se autoproclaman más "profesionales", por instalar a su parecer un sistema de mayor sofisticación para desarrollar esta tarea. A través de un pequeño molino, trituran la materia prima y la diluyen en agua, generando un barro líquido que por medio de pequeñas canalizaciones es direccionado a piscinas diseñadas e impermeabilizadas para tal efecto. Las impurezas quedan esta vez dispuestas también por medio del levigado, en la base del molino. Además, el agua para los artesanos coptos tiene un significado especial. La consideran un elemento sagrado que conecta directamente con Dios, circunstancia que les obliga a usar sin más la que haya sido bendecida previamente por un sacerdote. La búsqueda y apertura de pozos está ritualizada, al igual que la técnica del amasado. Con la finalidad de crear texturas homogéneas y eliminar burbujas de aire, los cristianos coptos de Garagos mezclan el barro imitando los gestos que los panaderos de su círculo de creencias aplican para modelar el pan, al cual se le asocia con el cuerpo de Cristo. Sin duda, un respeto añadido que les condiciona a no pisarlo nunca y a tratar con suma delicadeza el ajuar cerámico. Por el contrario, 


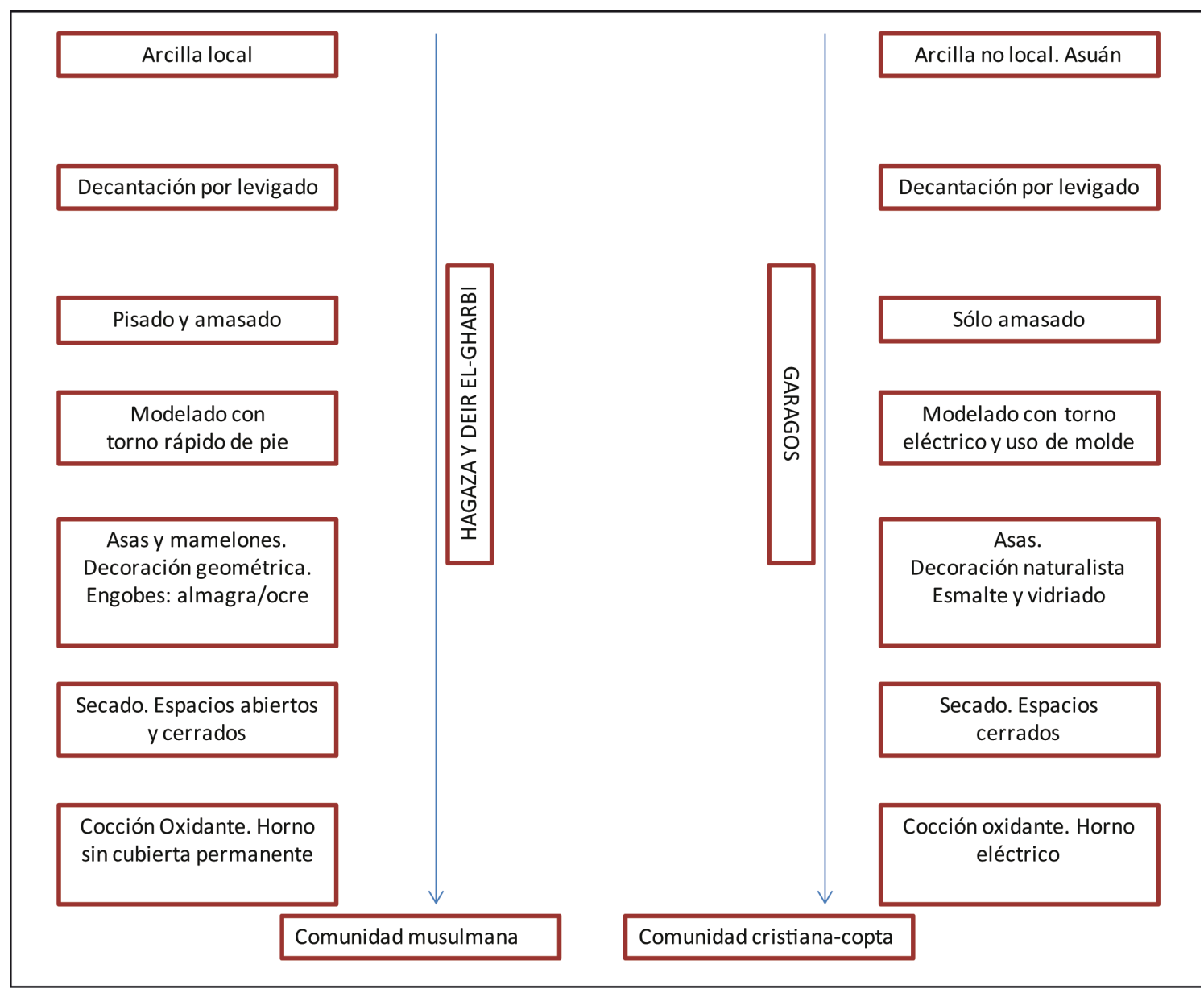

Figura 2. Cadenas técnico Operativas (CTO) cerámicas documentadas en comunidades alfareras musulmanas y cristiano-coptas.

las familias artesanas de Deir el-Gharbi y de Hagaza, al comprobar en la arcilla un grado óptimo de humedad, articulan una sucesión de gestos de trabajo mecánicos que transmiten de generación en generación y les permite pisar y amasar cantidades elevadas de material (Fig. 3). A priori, estos gestos no guardan un sincretismo religioso, pero sí se encargan de advertir mediante un lenguaje no verbal que pertenecen a una atmósfera y cultura social determinadas (Lemonnier 2012). Cualquier ámbito relacionado con la cadena productiva cerámica, sea éste perceptible o no, se convierte en un reflejo fiel de la materialidad en la que se inserta. La "eficacia técnica" se torna pues, en "eficacia social" (Lemonnier e. p.).

Sendas tradiciones alfareras albergan así mismo diferencias básicas en la fase que concierne con el modelado. A pesar de distar pocos kilómetros entre una comunidad y otra, la caracterización minuciosa de los gestos técni- cos nos habla de una heterogeneidad bastante marcada. Los cristianos-coptos, defensores y garantes de la entrada de la modernidad en Egipto, realizan las piezas con un torno rápido de pie, aunque generan la energía cinética con electricidad. Un pequeño motor les basta para no tener que accionar la rueda inferior valiéndose de sus extremidades. En contraste, los alfareros de Hagaza y Deir el-Gharbi continúan manteniendo un torno de pie tradicional y se resisten fuertemente a incorporar "avances" tecnológicos (Fig. 4). Por encima de todo, consideran que cualquier variación, por mínima que sea, condicionaría el éxito productivo. Una realidad que con toda certeza permite reafirmar el exacerbado conservadurismo del habitus adquirido (Bourdieu 1988), transformándose éste sólo en casos estrictamente necesarios (Roux y Miroschedji 2009). En relación con el corpus cerámico también son perceptibles divergencias considerables. 
A parte de variaciones sustanciales en la colocación del cuerpo y los gestos de posición de las manos en el proceso de levantado, los complejos alfareros de credo musulmán se especializan únicamente en la producción estandarizada de determinados tipos cerámicos, realizando de forma específica jarras, contenedores de almacenamiento o recipientes de cocina. Sin embargo, en Garagos manufacturan sin distinción alguna entre talleres la totalidad de enseres también estandarizados que su comunidad usa cotidianamente, dentro de los que incluimos, platos, vasos, tinajas, jarras, fuentes y ollas. Así mismo y por encargo crean figuras a modo de esculturas, que en el transcurso de la última generación han comenzado a ser fabricadas a molde. El deseo por identificarse con occidente y la consideración de la modernización como un proceso continuado, les lleva a realizar productos en serie que poco a poco relegan a lo que se asocia con lo viejo y antiguo. La pretensión por justificar la consolidación de prácticas económicas y sociales que les eran ajenas hasta hace unos años, ayudaría a entender con facilidad la incorporación de hábitos y estrategias de producción alternativas (Padilla Fernández e. p.).

Es en el transcurso de la fase del secado cuando las piezas, ya compuestas y en estado de cuero, reciben los atributos decorativos. Los cristianos coptos, independientemente de que los recipientes hayan sido modelados a torno o moldeados, incorporan por regla general ornamentos figurativos ligados a su modo de creencias. Peces, palomas o gallos se instituyen como los más comunes (Fig. 5). Los pigmentos y minerales para esmaltar y vidriar son comprados en Asuán e importados directamente desde Estados Unidos. A pesar de que son conscientes de que podrían obtener idénticos acabados con muestras locales, que son además bastante más sencillas de conseguir, prefieren adquirirlos fuera, al considerar esta adquisición un fuerte nexo con la modernidad y el mundo globalizado. En Hegaza y Deir elGharbi, sí aplican pigmentos producidos por ellos mismos, siendo los más comunes la almagra, para conseguir los colores rojo y ocre, y el caolín, para lograr el blanco. Normalmente los destinan a la obtención de engobados, predominando la técnica de la incisión para plasmar secuencias simétricas de líneas y zig zags. En este ámbito, las dos comunidades comparten la idea de que los motivos decorativos son locuciones manifiestas de su acervo cultural, y como tal, parte de su lenguaje simbólico (Gosselain 2011b).

La cocción, la última fase del proceso productivo, denota del mismo modo cambios y diferencias importantes. Los alfareros de Hagaza y Deir el-Gharbi todavía siguen creando y usando hornos tradicionales, es decir, estructuras bicamerales de tiro vertical, separadas por un suelo aparrillado, que sirve de soporte para depositar y colocar ordenadamente las piezas antes de su cocción. Con cubiertas no permanentes, controlan la oxidación valiéndose de pequeñas chimeneas construidas antes del encendido del horno. El rango de temperatura de cocción suele oscilar en torno a los 700$850{ }^{\circ} \mathrm{C}^{4}$, una temperatura óptima para obtener conjuntos cerámicos polifuncionales, destinados a servir preferentemente como enseres de almacenamiento y cocina. En Garagos hacen uso de complejos horneros completamente opuestos. No obstante, hasta 2005 y aunque con dimensiones y materiales (ladrillos) distintos, éstos sí ostentaban un funcionamiento idéntico al documentado en las comunidades de signo musulmán. El calor, provocado por la combustión de madera, ascendía verticalmente hacía la cámara de cocción, donde se producía según los propios alfareros la "mágica" transformación físico-química de arcilla a cerámica. A partir de 2005 la compra de hornos eléctricos unicamerales, considerados como más acordes a los nuevos tiempos, acabó con las cochuras manuales y de signo tradicional. Aún así, la ritualidad sigue condicionando con firmeza el devenir del considerado como punto clave para la consecución del éxito cerámico (Fig. 6). El empleo de estas nuevas estructuras no afecta en nada a la práctica siempre y cuando se tome la precaución de sacralizarlas. Evidentemente, las máquinas compradas fueron bendecidas a su llegada y en ellas, una vez que finaliza su función, se imprime con barro el signo de la cruz. De ahí que los cristianos coptos no demuelan e incluso reparen aquellos que ahora se consideran antiguos y no utilizan, ya que en ellos el aspecto simbólico continúa plenamente vigente. Los artesanos que rinden culto a Mahoma coinciden también en otorgar un valor sagrado a la cochura. Antes y después se dirigen a la mezquita más cercana para rezar y obtener la gracia de la divinidad. El ayuno de agua y comida en el intervalo de tiempo estimado (seis o siete horas) para desempeñar esta labor, suele ser la pauta habitual como señal de complacencia. La abstinencia sexual previa 

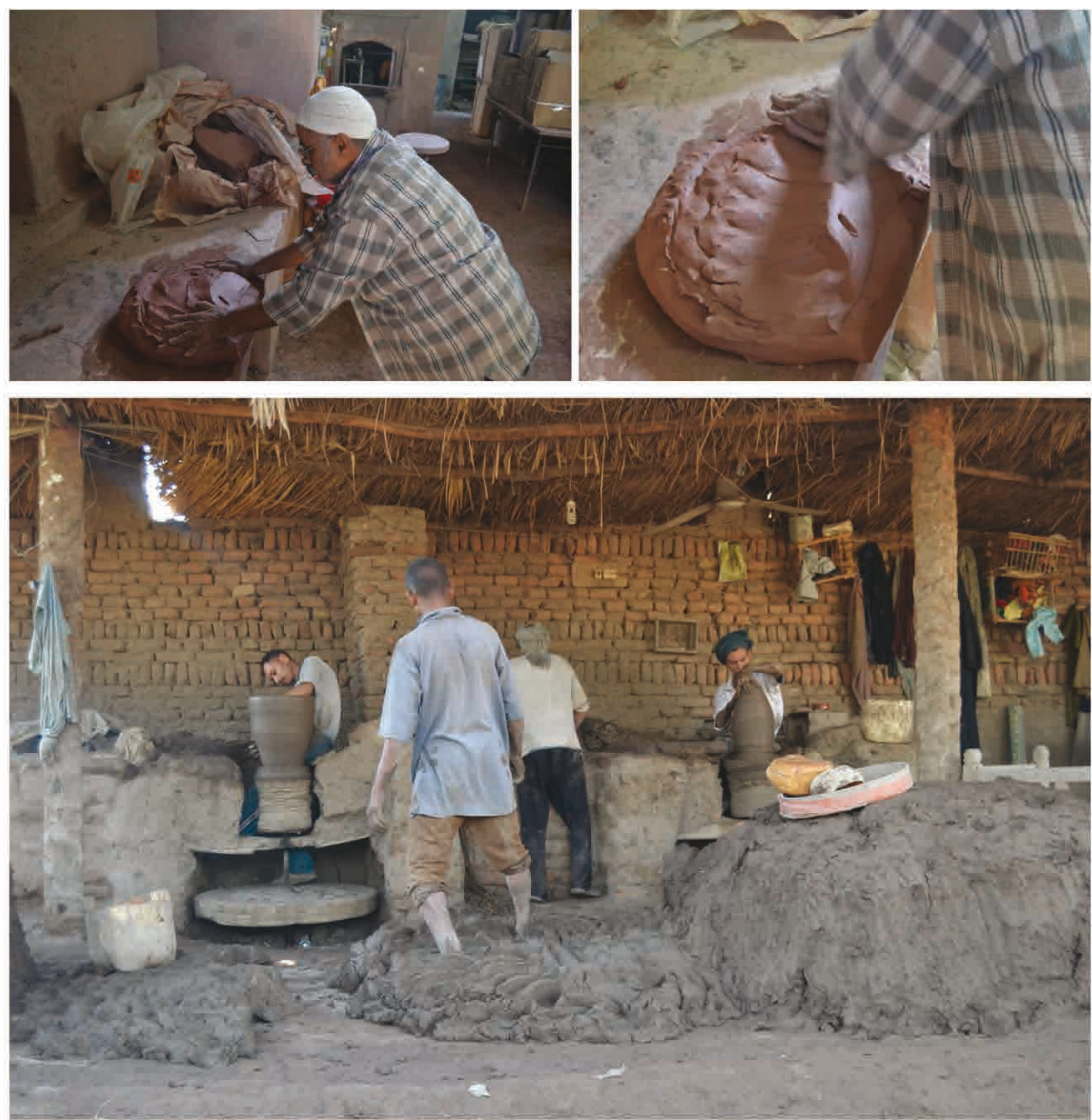

Figura 3. (Arriba). Alfarero de Garagos amasando barro. (Abajo) Proceso de pisado y amasado en Deir el-Gharbi.
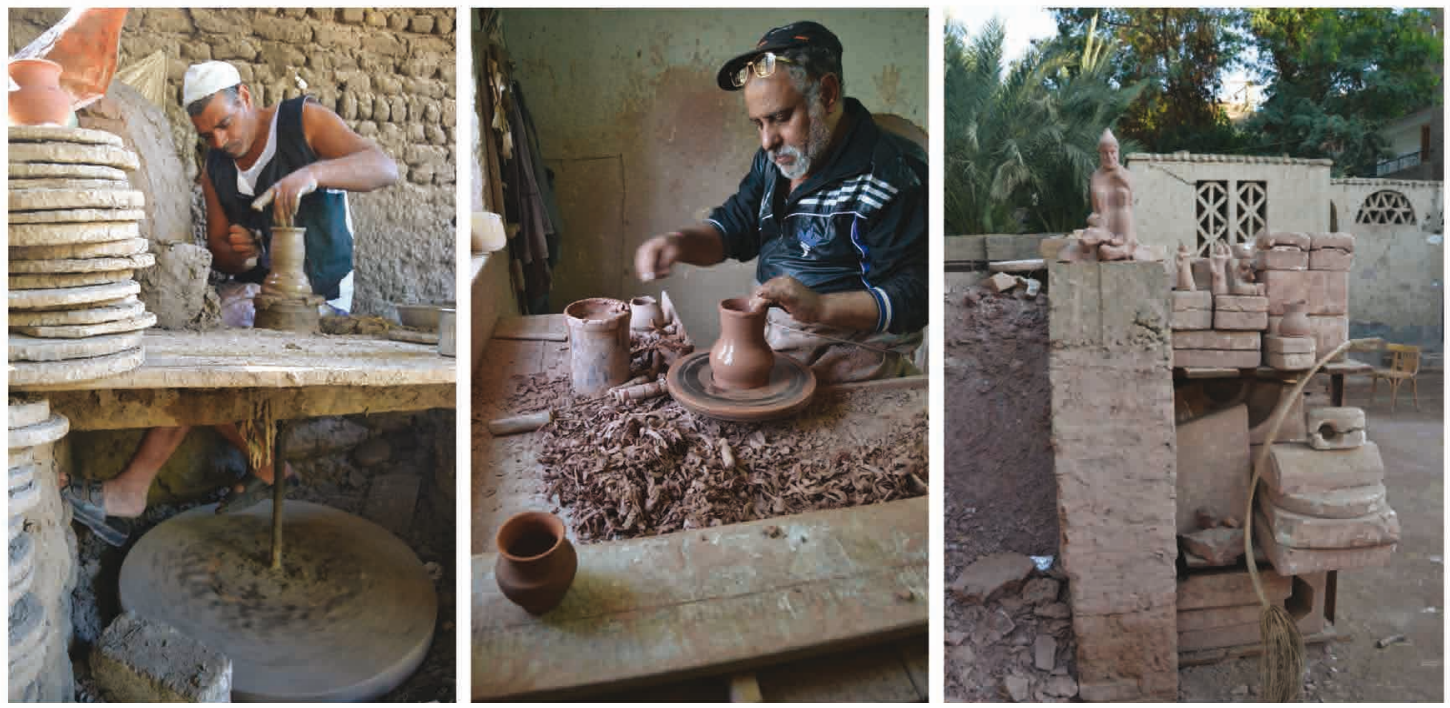

Figura 4. (Izquierda). Maestro alfarero de Hagaza modelando a torno rápido con una rueda de pie. (Centro). Maestro alfarero de Garagos modelando a torno rápido con una rueda de pie y con la ayuda de un pequeño motor eléctrico. (Derecha). Vaciados y Moldes de yeso de variada tipología documentados en Garagos. 

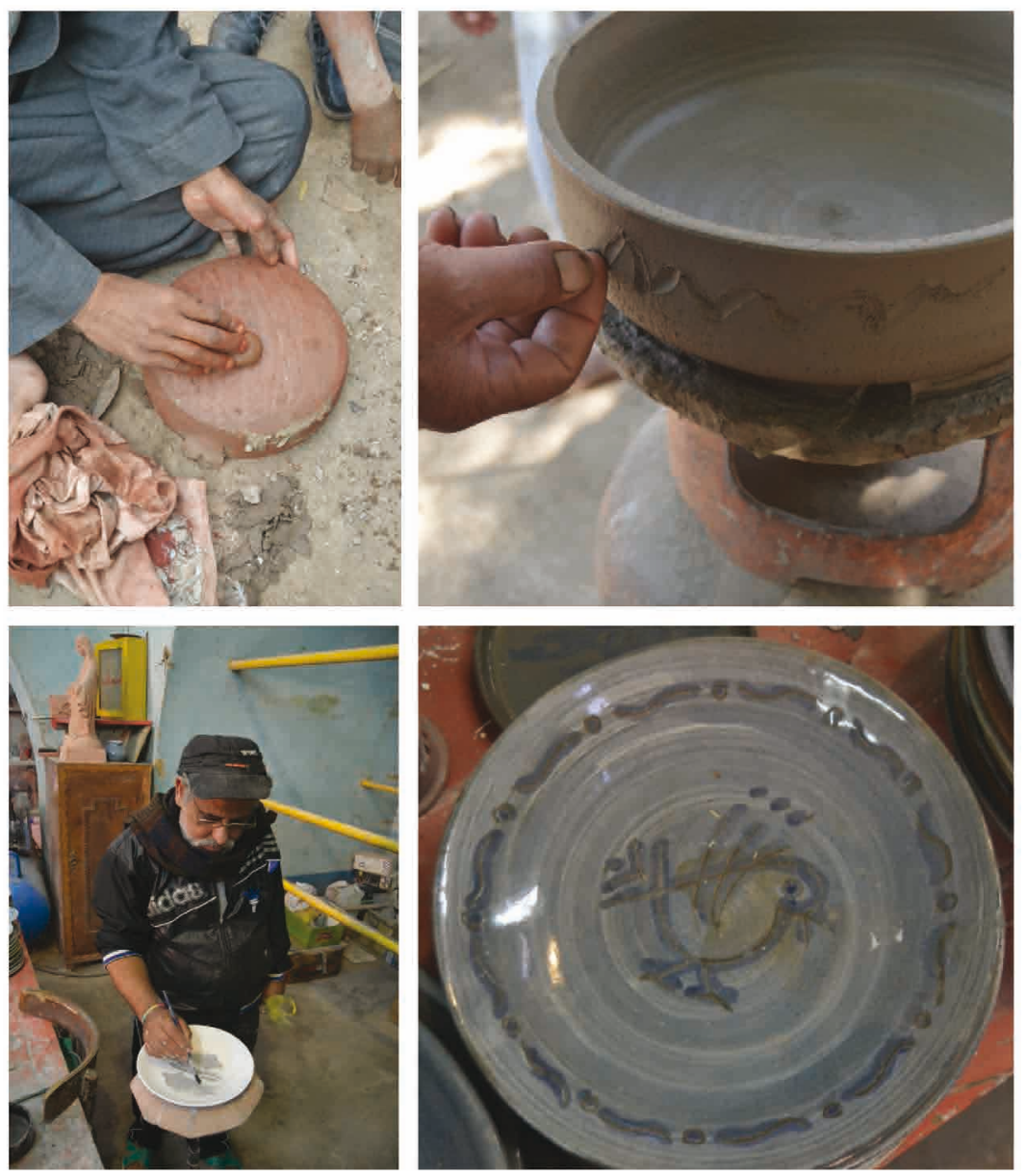

Figura 5. (Arriba). Decoraciones características de las producciones cerámicas musulmanas de la región de Luxor: asas, mamelones, engobados y motivos geométricos. (Abajo). Maestro alfarero de Garagos pintando con esmalte un plato secado en espacios cerrados. Comúnmente los motivos decorativos suelen ser naturalistas, haciendo especial hincapié en animales vinculados con la simbología cristiana: peces, palomas, gallos, etc.
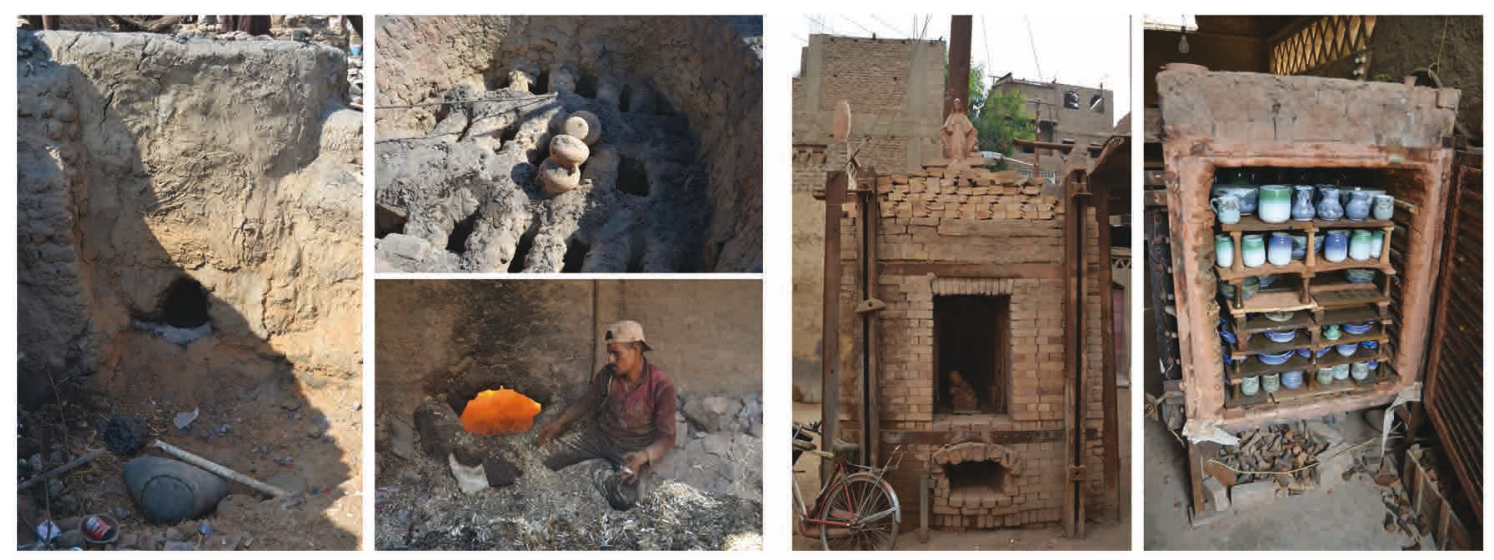

Figura 6. (Izquierda). Estructuras de combustión y proceso de cocción documentados en zos centros alfareros musulmanes de Hagaza y Deir el-Gharbi. (Derecha). Hornos característicos del enclave cristianocopto de Garagos. El primero está en desuso, utilizándose únicamente aquél que funciona con electricidad. 
al proceso se erige de semejante manera como una norma frecuente.

Intentar entender el dominio social en su contexto cultural, nos lleva a comprender que "los objetos somos nosotros" (Webmoor y Witmore 2008). Sin miedo a equivocarnos, podemos plantear que los alfareros cristianos y musulmanes de la región de Luxor, desde una posición consciente, establecen líneas de trabajo y frecuencias de aprendizaje opuestas en base a un régimen de creencias explícito. El estudio detallado tanto del uso como de la distribución de las cerámicas, nos ayuda a confirmar que aquí no tienen cabida criterios vinculados con el azar. Es sugerente atestiguar cómo los artesanos musulmanes crean tipos funcionales concretos que son consumidos de forma exclusiva por los grupos de confesión islámica, el 90\% total de la población. Presumiblemente, el colectivo de cristianos coptos se vale únicamente de lo hecho por sus alfareros, descartando la compra y uso de cualquier recipiente cerámico, independientemente de su tipología, que no haya sido modelado conforme a su dogma de fe. En cuanto a la comercialización, si cabe decir que existen divergencias palpables. En el ámbito musulmán es la figura del intermediario la que se encarga de vender las producciones a pie de calle en puestos al aire libre o al por mayor en diversos puntos del estado. Los cristianos coptos, en cambio, se abastecen dirigiéndose directamente al taller, sin la necesidad de recurrir a terceros. Eso sí, la venta efectuada a distritos provinciales lejanos como Alejandría, El Cairo o Asuán, es gestionada por los centros eclesiales que también controlan el negocio vinculado a los turistas.

\section{Producción alfarera e identidad social}

Fruto de las investigaciones llevadas a cabo en la región egipcia de Luxor, podemos aseverar que la cerámica se convierte en un mecanismo potente de atribución social. Todo apunta a que, desde la concepción misma del producto y a través del aprendizaje y transmisión de una serie de gestos técnicos, en los conjuntos cerámicos quedan plasmadas ideologías y construcciones identitarias precisas (Dobres 2000). Hasta ahora hemos sido capaces de discernir el perfil vertebrador de la religión en la esfera de lo cotidiano, aunque cabe preguntarnos si es ésta la única que se dispone como definidora cultural de una comunidad específica de per- sonas. Si bien es indiscutible que el dogma de fe despliega de facto una fuerte imagen de unidad frente a la otredad, la distinción de ciertos cambios y actitudes en el plano de lo tecnológico asentiría el reconocimiento de identidades más complejas y repletas de intersecciones. La campaña de 2014 centró esfuerzos justamente en este aspecto, escudriñar esa posible "multiplicidad de variables" (Sánchez Elipe 2015: 129), con el objetivo de entender la realidad intragrupal de las comunidades musulmana y cristiana-copta.

Basta decir que, ya en los primeros compases de la investigación caímos en la cuenta de que el puzle social era considerablemente más complicado de lo que en un principio se había imaginado. En primer lugar merece la pena destacar la relación efectiva entre trabajo alfarero y poder. De forma prácticamente inconsciente los alfareros toman decisiones técnicas que sustentan un "régimen de verdad" (Foucault 1992: 187), cimentado en un modelo ontológico de claro signo patriarcal. En este aspecto, musulmanes y cristianos se asemejan al desarrollar ambos una transmisión cerrada del conocimiento alfarero. En Hagaza y Deir el-Gharbi los concebidos como individuos infantiles masculinos son separados de los femeninos desde los cuatro a cinco años aproximadamente, para emprender caminos de aprendizaje diferentes. Las niñas son apartadas de todo aprendizaje que conlleve el manejo de gestos técnicos relacionados directamente con la producción cerámica, mientras que los niños inician una instrucción marcada, centrada en la imitación de los gestos técnicos considerados como fundamentales para la fabricación de elementos cerámicos. Concretamente, inician su formación asimilando los procesos de pisado y amasado de la arcilla, dos actividades que combinan indistintamente con la realización de tareas externas, tales como el aprovisionamiento y transporte de las materias primas, el acarreo de piezas recién modeladas hacia los secaderos, o el almacenamiento de todo el material recién salido del horno. A posteriori, el dominio de tales acciones les otorga el derecho a emular los gestos técnicos aplicados durante la fase del modelado. Años más tarde, tras una evaluación positiva por parte de los maestros mas veteranos del taller y la confirmación efectiva de la adquisición, mediante imitación repetitiva, de un grado óptimo de pericia técnica que permite un dominio preciso del torno, los hasta entonces aprendices comienzan a ser 
considerados como verdaderos maestros, pudiendo participar de forma activa a partir de entonces en los procesos vinculados con la cocción. En Garagos, la educación sesgada por género se inicia a los siete años, una vez pasado el rito de la comunión. Por lo demás, el proceso de aprendizaje no diverge en absoluto del documentado en las comunidades musulmanas, encontrándonos pues ante talleres de estructuración piramidal, regidos por maestros expertos a los que nunca se les cuestiona.

El control social y absoluto de las etapas de modelado y cocción fortalece la individualidad masculina del "yo" (Hernando 2002: 56-58) y relega lo femenino a un segundo término. Se fomenta lo que Almudena Hernando (2012) describe como una "fantasía", que comienza a construirse desde la niñez. En la esfera musulmana las mujeres sí participan activamente como ayudantes en varias fases de la secuencia productiva cerámica, pero se les tiene prohibida la participación en aquellas que están ligadas al torneado de las piezas y su cocción. A parte de interiorizar los gestos relacionados con los quehaceres domésticos, obtienen a través de la observación directa el saber de facetas asociadas con la imagen del aprendiz y, por tanto, consideradas de carácter menor. La no inclusión en los ciclos conceptuados como vitales, es decir el modelado y la cocción, es justificada incluso con la creación de tabús artesanales que tachan al mundo femenino de impuro y propiciador de dificultar e interrumpir la transformación físico-química de la arcilla en cerámica. En la órbita cristiana la marginación es aún mayor. El género femenino se encuentra literalmente apartado en lo que concierne a las labores alfareras, limitando su capacidad de acción a las prestezas decorativas. Básicamente, las mujeres con su papel subsidiario asientan los mecanismos sociales que otorgan respeto y superioridad a aquel "ser individual" (Hernando 2008: 64) y masculino que por ley divina dispone de un elevado nivel de conocimientos y habilidades técnicas.

Profundizar en la huella social de estas cadenas operativas permite en segunda instancia hablar también, y en este caso sólo en el ámbito musulmán, de una jerarquización de estatus interna y articulada en lo que a elaboración de

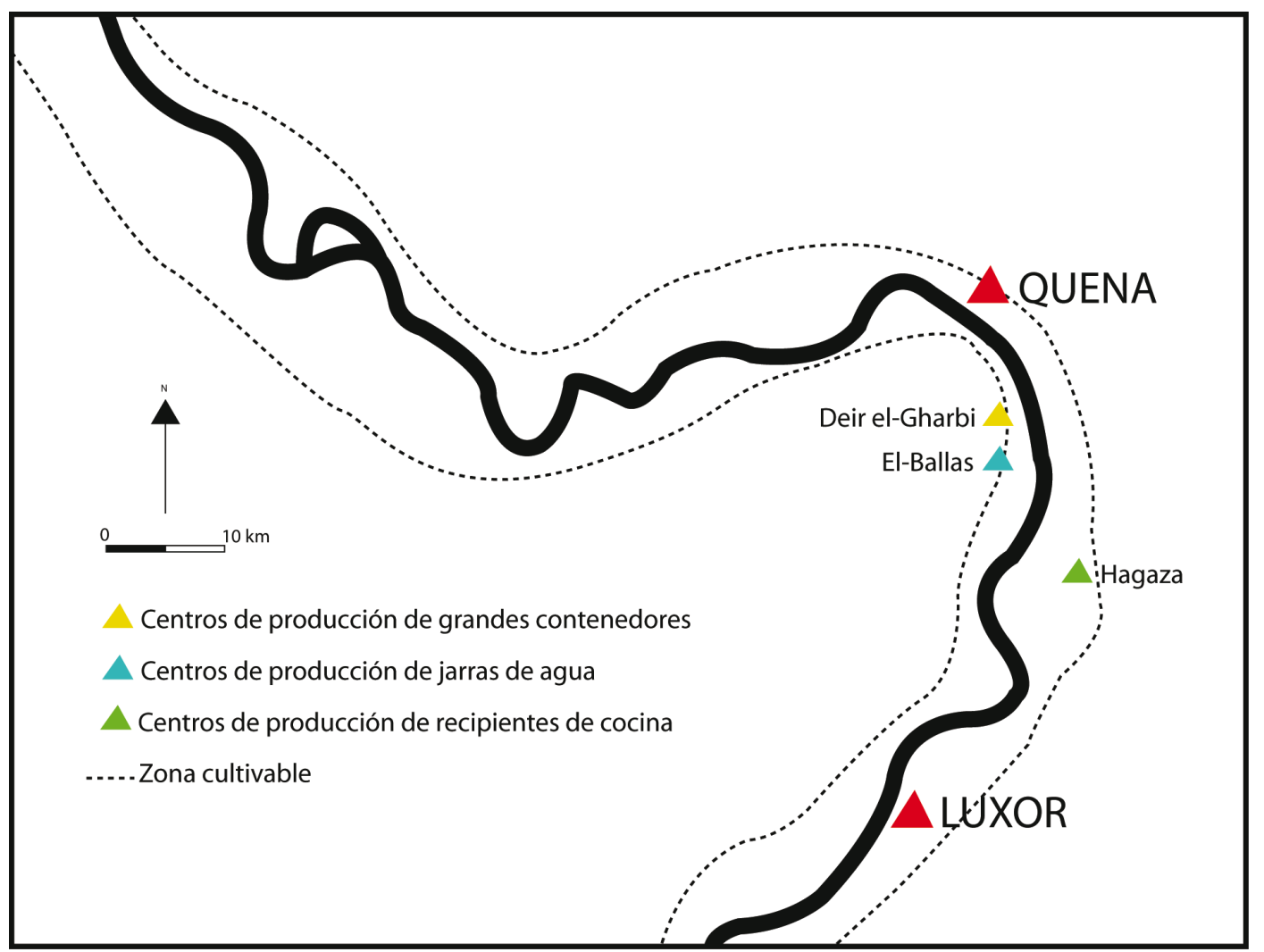

Figura 7. Ubicación de los distintos centros productores cerámicos musulmanes atestiguados en la región de Luxor. 

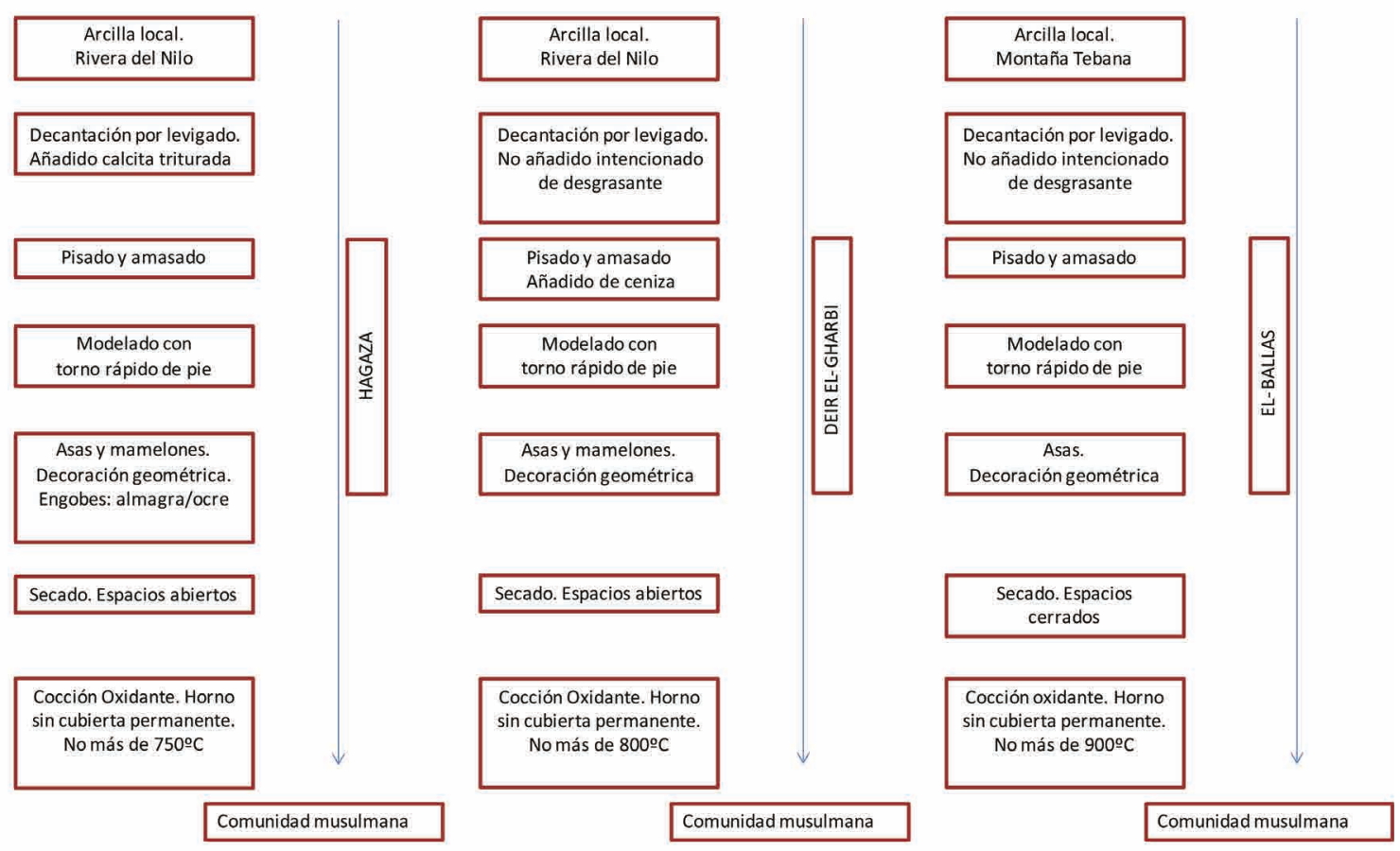

Figura 8. Cadenas Técnico Operativas (CTO) de las cerámicas desarrolladas en Deir el-Gharbi, la aldea de El-Ballas y Hagaza.

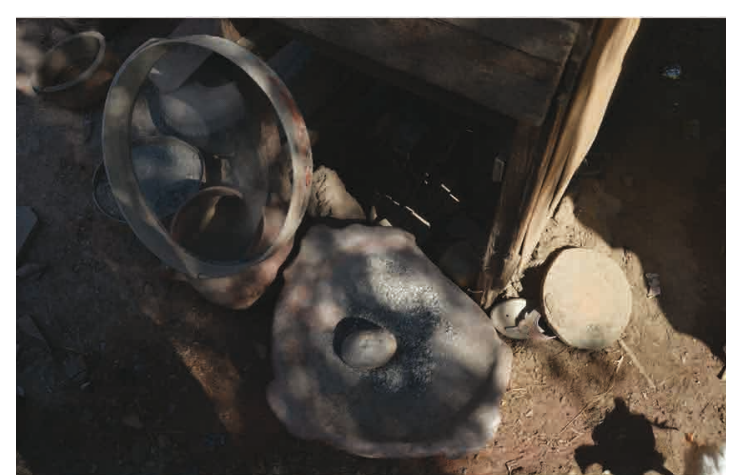

tipos cerámicos se refiere. En Deir el-Gharbi y Hagaza han sido documentados repertorios variados que exigen una serie de mecanismos, etapas y/o gestos determinados (Fig. 7). Por ejemplo, la obra de ollas y cazuelas comporta el manejo de tácticas especiales, que difieren de las designadas para crear grandes contenedores, cántaros o jarras. Estas alteraciones, convertidas en costumbre a través de repeticiones continuadas en el tiempo y transmitidas verticalmente de generación en generación, se descubren en todas las fases del proceso productivo (Fig. 8).

Como ya dejamos entrever en líneas ante-

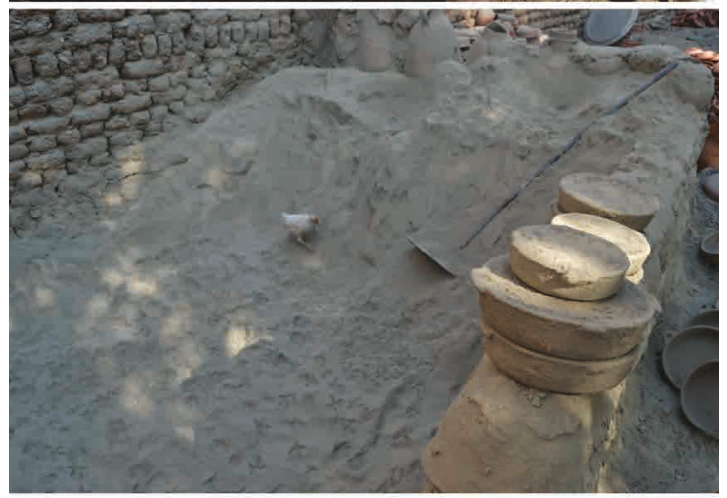
riores, los alfares emplazados en el término de Hagaza se dedican en exclusiva a la manufactura de recipientes conectados con la preparación de alimentos. Para conseguirlo, hacen

Figura 9. (Arriba). Mortero de granito en el que los alfareros de Hagaza machacan "hamar", calcita que a posteriori y durante el proceso de decantación se añade a la pasta arcillosa resultante. (Abajo). Almacenamiento de "hamar" en una pequeña despensa próxima a la zona de depurado. 

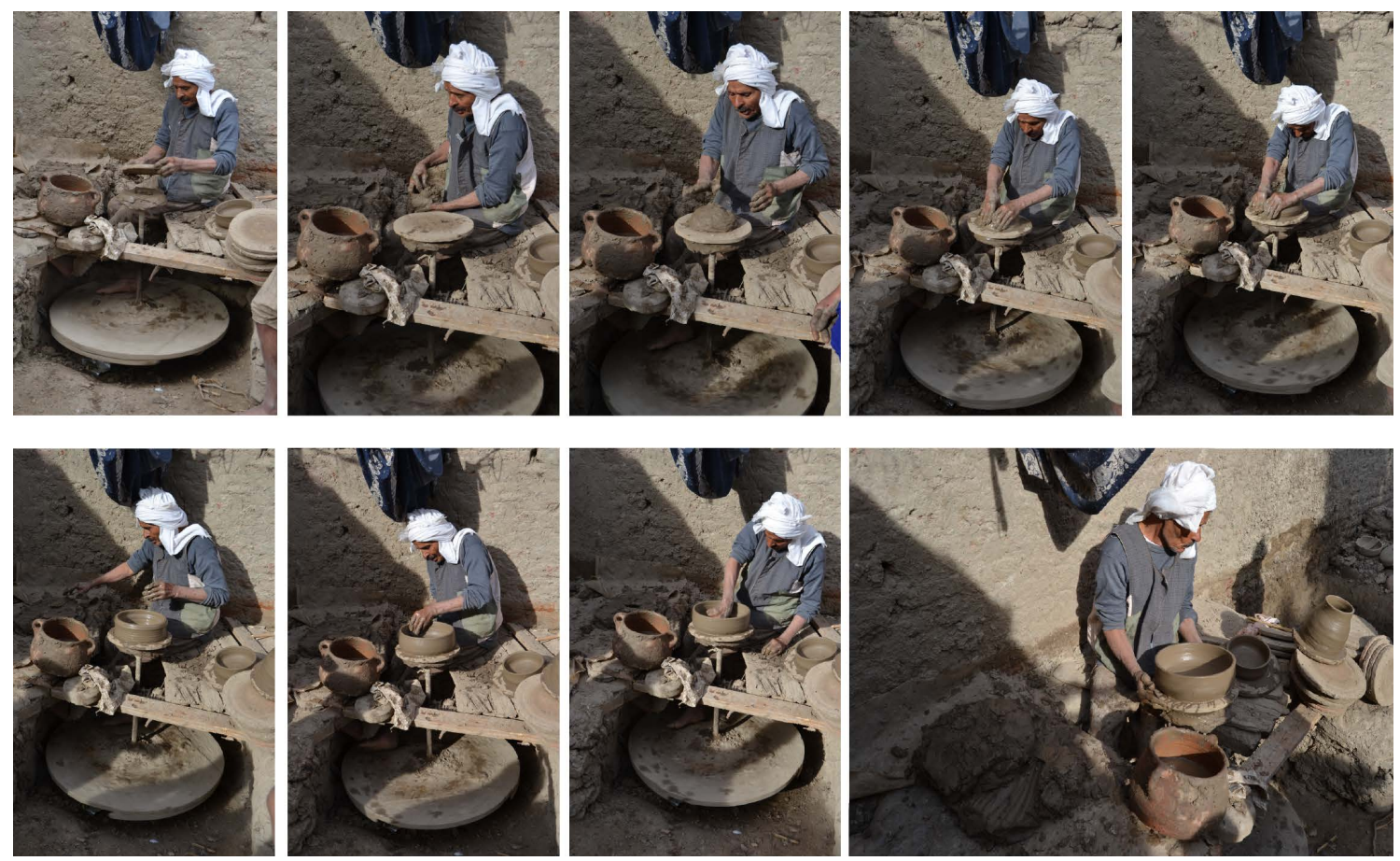

Figura 10. Secuencia lineal de gestos técnicos aplicada para modelar cazuelas en Hagaza.

uso de sedimentos arcillosos de origen secundario que extraen de la cercana rivera del Nilo y sus canales. Seguidamente y en el tránsito del proceso de decantación, añaden a la pasta resultante calcita triturada. Este mineral, denominado por ellos con el vocablo arábigo "Hamar" (roca blanda), se obtiene de los rebordes montañosos calizos circundantes con el propósito de ser utilizado como desgrasante (Fig. 9). Una vez que ha sido molido, se mezcla con la arcilla para adquirir un material de trabajo apto para lograr recipientes de cocina funcionales, es decir, un material que sea fuerte, homogéneo y se caracterice por su buen funcionamiento mecánico (Velde y Druc 1999). A continuación e inmediatamente después de pisar y amasar, los maestros alfareros forjan en barro tres tipos concretos mediante la ejecución de ocho gestos o posiciones de mano (Fig. 10). Elaboran tres tamaños diferentes de cazuelas, ollas en dos mesuras y jarras con cuatro volúmenes, al mismo tiempo que dos modalidades de tapadera, adaptadas respectivamente al diámetro de la muestra formal (Fig. 11). Tras su decoración con motivos geométricos y la aplicación de un engobado mayoritariamente en almagra que ayuda a sellar poros superficiales, la cocción en atmósfera oxidante tiene lugar en pequeñas estructuras hornarias bicamerales que no alcanzan curvas de temperatura superiores a los $750{ }^{\circ} \mathrm{C}$, un criterio técnico que unido al empleo sistemático de la calcita como desgrasante comporta un aumento considerable de la resistencia térmica de las piezas, consolidándolas como una vajilla excelente para las prácticas culinarias (Albero 2008). Verdaderamente, los maestros alfareros de Hagaza parten del hábito y la experiencia para conocer a la perfección todo lo que atañe con la fabricación de cerámicas planteadas para resistir exposiciones a fuego reiteradas.

En cambio, los alfareros asentados en Deir el-Gharbi se dedican a la confección de recipientes de grandes dimensiones, predestinados fundamentalmente al almacenamiento de grano, maíz y demás provisiones sólidas, aunque a menudo sean recicladas también para albergar agua. Las tácticas que emplean para la adquisición de la materia prima son similares a las apreciadas en los talleres cerámicos de Hagaza, valiéndose de arcillas accesibles y acumuladas en zonas de regueros adyacentes. La decantación de estos sedimentos de origen secundario se consuma en pequeñas piletas excavadas en el suelo, donde en contraposición con lo avistado en los complejos que se centran en producciones de cocina, no se añade de forma premeditada ningún desgrasante. En esta ocasión, la tradición alfarera impone un agregado intencionado de ceniza durante el proceso de amasado. Con 

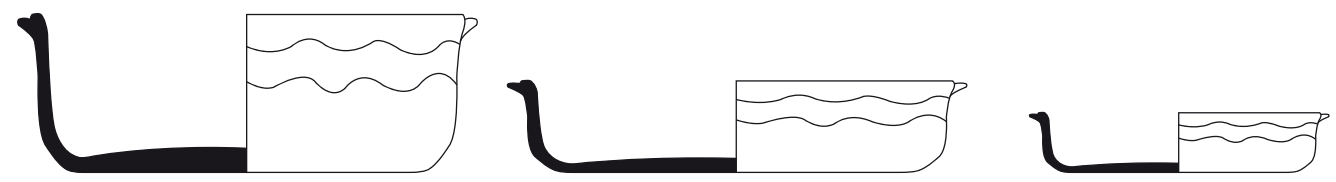

1
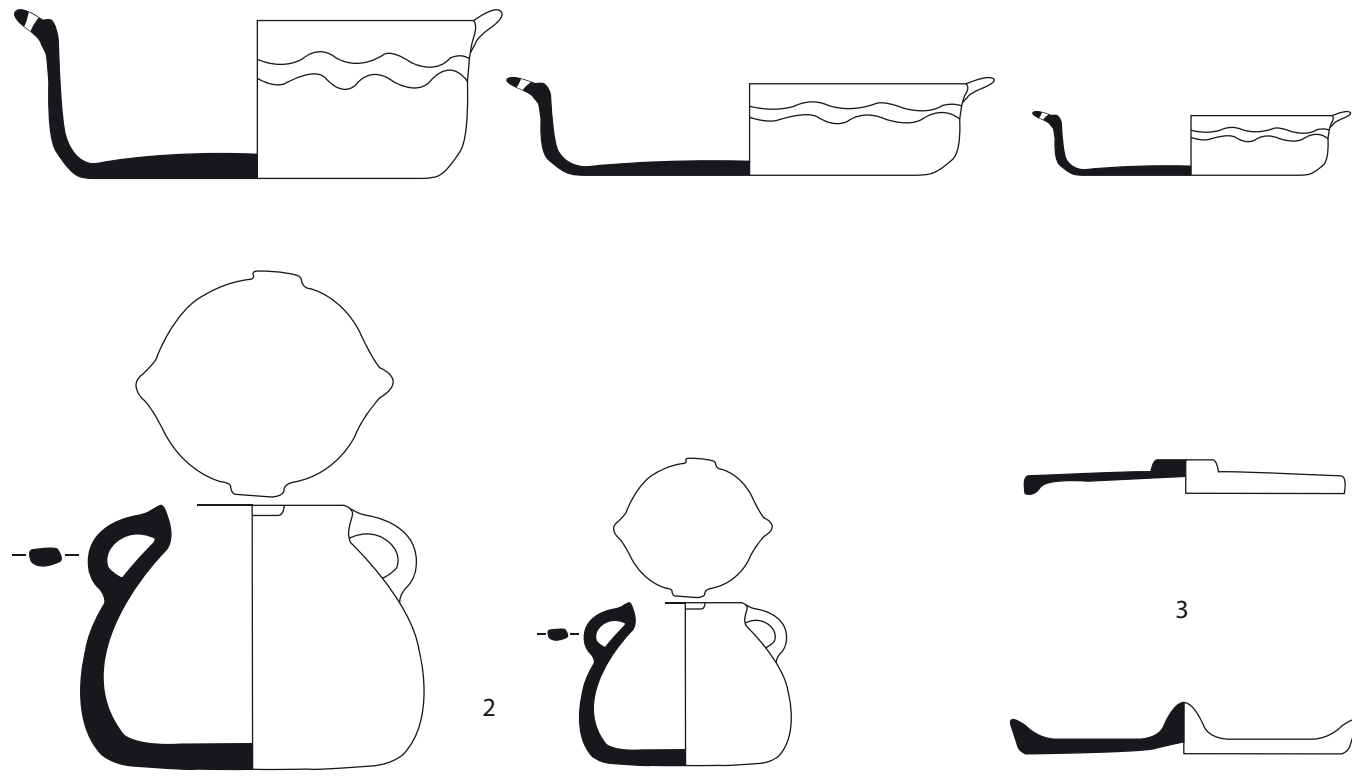

3

2
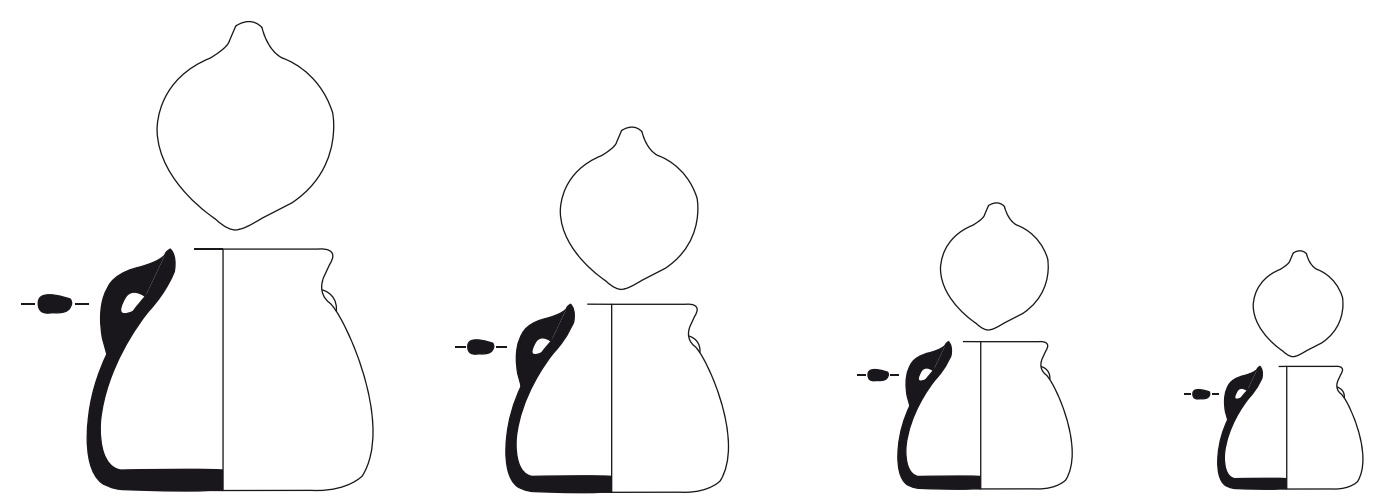

4

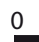

$20 \mathrm{~cm}$

Figura 11. Conjunto formal de cocina realizado por los talleres alfareros de Hagaza: 1. cazuelas, con o sin asa perforada, en tres tamaños. 2. Ollas con dos volúmenes diferentes. 3. Tapaderas en dos modalidades.

4. Jarras con cuatro cuerpos distintos. 

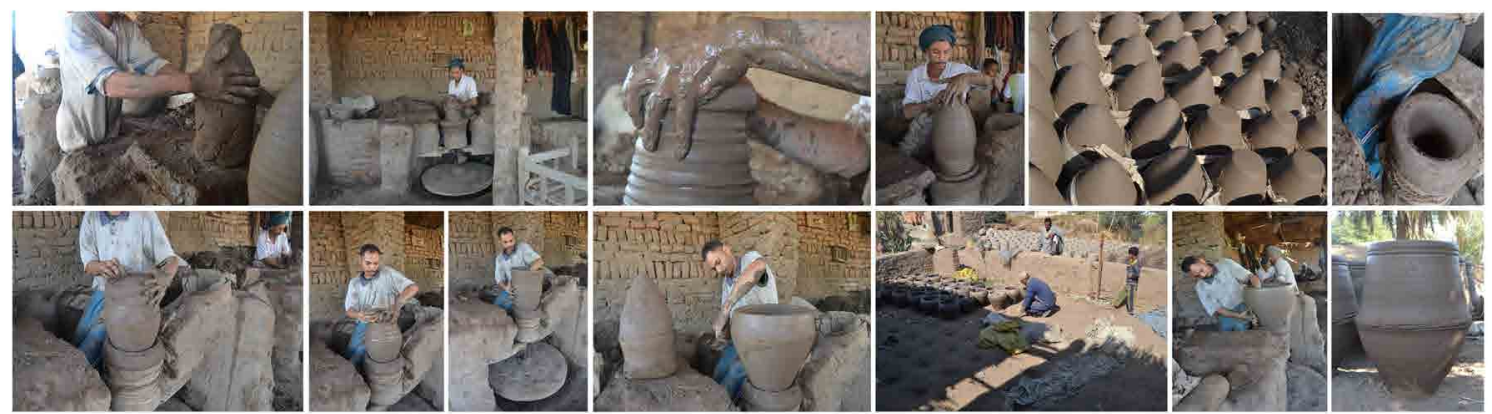

Figura 12. Secuencia lineal de gestos técnicos aplicada para modelar contenedores en Deir el-Gharbi.

la premisa de conferir a la pasta una densidad menor, a la par que un grado mayor de impermeabilidad, se reciclan los restos resultantes de la combustión de madera de palmera habida en la fase de cocción. Para crear dos modalidades $\mathrm{y}$ tres volúmenes de contenedor, uno con fondo plano y otro con base en pico, los maestros alfareros dividen el trabajo del modelado en tres etapas compuestas cada una por cinco gestos o posiciones de mano (Fig. 12 y 13). En primer lugar se procede a la manufactura del cuerpo inferior, que transcurrido un lapso de tiempo de tres a cuatro horas, es modificado de nuevo para acometer el levantado de las paredes. Por último, las piezas adquieren su morfología final seis horas más tarde, con el articulado de una porción extra de barro sobre lo ya moldeado y en estado de cuero. La cochura, llevada a cabo después del secado, alcanza atmósferas oxidantes y temperaturas próximas a los $750-800{ }^{\circ} \mathrm{C}$.

Los alfareros que viven en la Aldea de ElBallas, muy próxima al Núcleo poblacional de Deir el-Gharbi, no producen ni ollas ni contenedores, sino cántaros. Concretamente, fabrican pequeñas ánforas destinadas a contener y almacenar agua (Nicholson 2009). Considerados en sí mismos como especialistas de un importante tipo cerámico, los artesanos de esta pequeña localidad se dedican a reproducir un quehacer técnico particular y repleto de variantes. La obligación de seleccionar arcillas con unas características particulares, les conduce a usar un tipo de materia prima arcillosa específico. Con la intención de engendrar vasos impermeables, hacen uso de filones primarios de arcilla calcárea, situados a sólo cinco kilómetros de distancia, justo en la cadena montañosa que delimita el inicio del desierto en su parte occidental. De la explotación y comercialización del mineral no se encargan los artesanos, sino un gremio independiente de mineros que vive de la compra-venta (Nicholson y Patterson 1985), operando en cierto modo lógicas similares a las apreciadas en tal caso dentro del ámbito copto. Así pues, la arcilla calcárea ostenta un valor material añadido, un hecho que también se manifiesta como tal en las actividades ligadas con su purificación y decantación. El deseo de manufacturar productos de alta compacidad y cocciones a elevadas temperaturas, les conduce a desempeñar una técnica de levigado concienzuda y centrada en la eliminación de caliches, en la que no se contempla la añadidura de elementos externos como desgrasantes. Los artesanos condicionan el éxito de la secuencia productiva a la preparación de una masa fina y poco porosa con la que poder aplicar sin contratiempos las veintidós posiciones de mano necesarias para sacar el perfil de su cántaro particular (Nicholson y Patterson 1991). En dos tiempos, y desarrollando un grado de pericia técnica notable, formalizan tres modelos de diferente capacidad (Fig. 13). La fase del secado, realizada en un recinto puntual completamente techado y dotado de ventilación, constata del mismo modo la singularidad de este proceso productivo. Se es absolutamente consciente de que una incidencia solar plena en piezas con dichas propiedades físicas, acabaría por resquebrajar una buena parte de éstas (García Roselló y Calvo Trias 2013). Las cocciones no difieren de las descubiertas en el resto de alfares de tradición musulmana, salvo por dos aspectos. Las estructuras hornarias adquieren dimensiones considerables de tres a cuatro metros de diámetro y son compartidas en su conjunto por varias familias alfareras, las cuales, y actuando en consecuencia para conseguir un mayor hermetismo de las superficies cerámicas, efectúan curvas térmicas que alcanzan los $850{ }^{\circ} \mathrm{C}$ (Nicholson y Patterson 1989) (Fig. 14). 


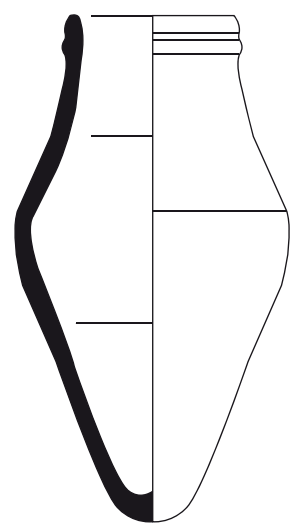

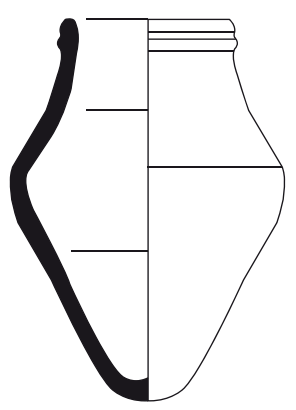
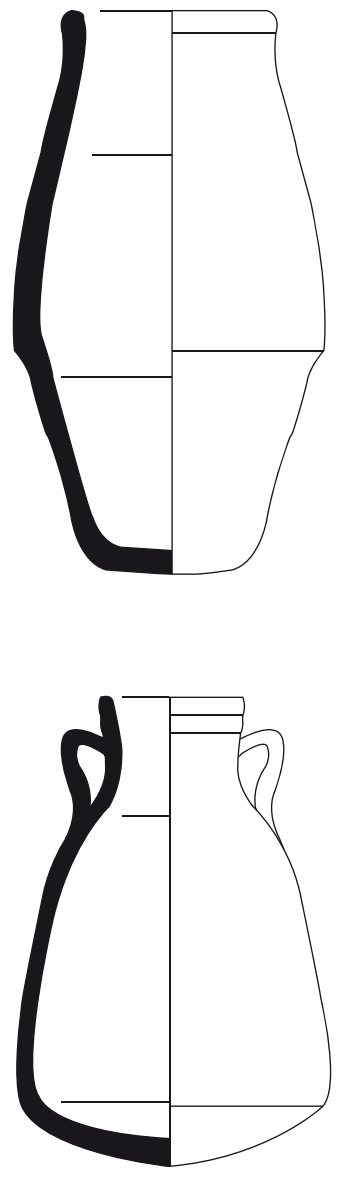

1
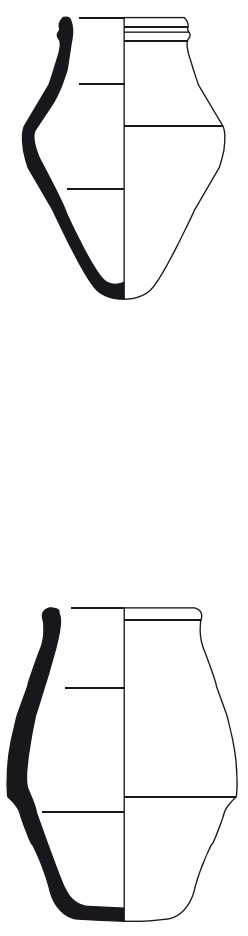

2

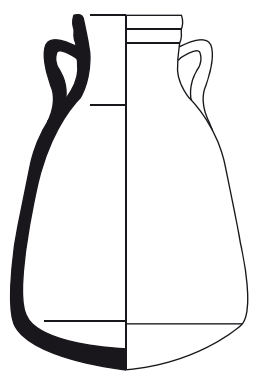

3

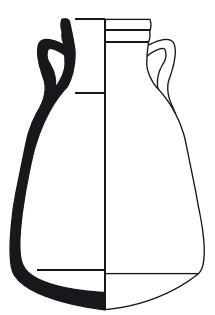

0 $40 \mathrm{~cm}$

Figura 13. Conjunto formal de recipientes elaborado por los talleres alfareros de Deir el-Gharbi: 1. Contenedores polifuncionales con base en pico. 2. Tinajas de almacenamiento destinadas al depósito de provisiones sólidas. Conjunto formal de recipientes elaborado por los talleres alfareros de la aldea de El-Ballas: 3. Jarras de agua. 

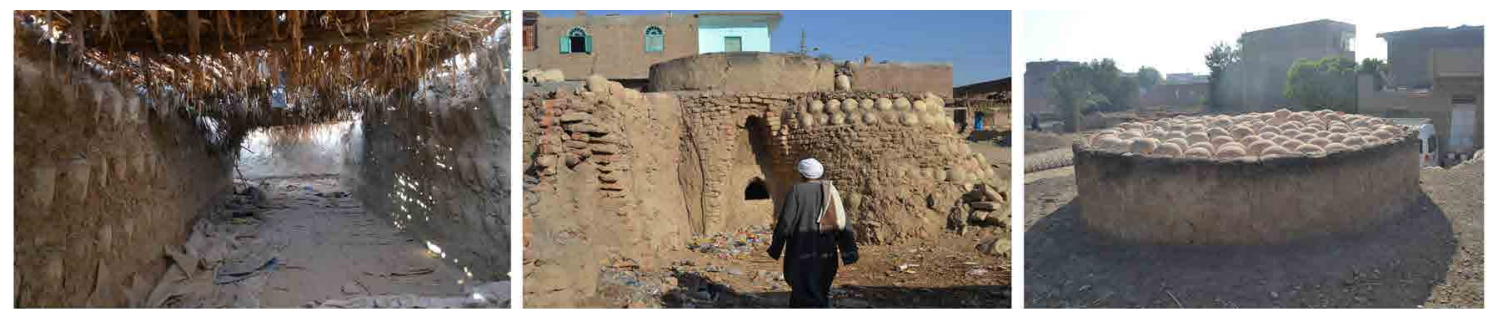

Figura 14. (Izquierda). Espacio cerrado dedicado en exclusiva al secado de las jarras de agua manufacturadas en la aldea de El-Ballas. (Centro y derecha). Estructuras hornarias comunales construidas en la aldea de El-Ballas.

Si prestamos atención y hacemos una valoración integral de las informaciones recogidas, es evidente que todos los talleres artesanos son musulmanes y comparten una identidad común, pero igualmente lo es la organización de un sistema social complejo y estratégicamente articulado que interacciona con su sentir religioso. Esta multiplicidad de prácticas viene prescrita por factores intrínsecos, que en virtud de una función determinada y su estimación sustancial, han estipulado una pirámide artesanal alineada en base al conocimiento y ejecución de nociones técnicas concretas. De este modo, la fabricación de cerámica de cocina conlleva la adscripción social al escalafón más bajo de la maestría artesana. Los alfareros de Hagaza trabajan todos los días del año y sus productos, aparte de ser los más convencionales, son los más económicos. La producción de grandes contenedores posee una gradación algo mayor. El conocimiento de estos gestos técnicos permite la elaboración de un ajuar primordial, tanto para conservar recursos agrícolas o ganaderos como para disponer de agua en puntos que se suponen comunales: intersecciones de caminos, carreteras, paradas de autobús, etc. Además, la adquisición de un vaso de tal singularidad prevé un gasto superior, otorgando a sus artífices de recursos económicos suficientes como para cesar su actividad en cortos periodos de tiempo y dedicarse subsidiariamente al laboreo agrícola. No obstante, es en los alfareros de El-Ballas sobre quienes recae el máximo prestigio, obtenido principalmente por el valor funcional que la comunidad en su conjunto otorga a los recipientes que sólo ellos saben fabricar. La importancia que adquiere en un medio quasi-desértico el acopio hídrico y su mantenimiento en condiciones aptas hace que estos cántaros sean considerados esenciales, concediendo a sus productores amplios beneficios pecuniarios y una ocupación claramente estacional. Durante los meses de noviembre a febrero invierten su tiempo en el reparo de los hornos, la limpieza de los tornos, la comercialización de las existencias sobrantes y el cultivo de sus tierras en propiedad.

La cultura cerámica atribuible al colectivo musulmán atiende a un paisaje de prácticas diverso y repleto de gestos, habilidades y niveles de pericia técnica variados, que asientan la jerarquización interna del gremio alfarero y enriquecen su identidad global. Eso sí, en ningún caso los cambios atisbados en la cadena operativa diluyen el mensaje prioritario de adhesión a una óptica particular de apreciar y concebir el mundo.

\section{Conclusiones}

Las apreciaciones escritas en el transcurso de estas líneas, demuestran que la cerámica encierra lenguajes sociales cargados de códigos identitarios. En este sentido, la disciplina etnoarqueológica se convierte en la herramienta ideal con la que poder registrar, por un lado, la idiosincrasia de comunidades humanas todavía preindustriales y amenazadas por el avance de la globalización occidental, y por otro, plantear pautas de la vida social que han pasado tradicionalmente desapercibidas, como la connivencia en un mismo territorio de diferentes identidades regidas por sus propias reglas y gestos técnicos. La puesta en marcha de un análisis antropológico del objeto cerámico, pone de manifiesto que no todo es tan sencillo $\mathrm{y}$ acorde a lo que siempre presuponemos desde nuestra oportuna concepción holística del mundo. En Egipto, por ejemplo, el día a día se encuentra condicionado por la religión y el uso y consumo de bienes específicos.

Marcando diferencias con respecto a la versión oficial, no existe una única e indivi- 
sible identidad étnica egipcia. La bandera y las fronteras del país del Nilo esconden una pluralidad de identidades, que son las que verdaderamente cimentan la construcción de las relaciones sociales. El sentimiento de creencia en un más allá cristiano o musulmán origina una brecha bastante importante que implica la consolidación de dos realidades contrapuestas, que no interactúan entre sí y tratan en la medida de lo posible de separarse y fijar distancias. En esencia dos realidades confrontadas, que sin embargo si comparten la imposición de un régimen social asentado sobre principios sagrados y sometido a una identidad individualizada que concede al "yo" masculino un predominio frente a lo femenino. Un poder y un estatus que, al menos en la esfera islámica, también se estratifica en orden a la noción de una serie de conocimientos considerados por el grupo de mayor o menor importancia social.

Si trazamos una perspectiva de conjunto, no resulta difícil hacerse a la idea del hori- zonte investigador abierto en el transcurso de estos años. En un entorno académico de corte tradicional donde prima con frecuencia lo estrictamente cuantificable y perceptible, se ha conseguido dar importancia a lo que con asiduidad permanece olvidado, revalidando la cerámica como un nexo útil de unión entre cultura y materialidad. $\mathrm{Y}$ es que todo, hasta el más mínimo gesto forma parte de la cultura. El entendimiento de la producción, distribución y consumo de la cerámica, ha permitido una aproximación más cercana a cada una de las acciones sociales desarrolladas en cualquier ámbito de la vida cotidiana. Aún así, todavía queda un largo camino por recorrer. En clave de futuro se pretende llevar a cabo el objetivo de ampliar la exploración a regiones vecinas de fuerte tradición alfarera, con el pretexto de completar la información documentada en la zona de Luxor. Ojalá nuevos descubrimientos y más sorpresas nos acompañen en el discurrir de esta larga senda.

\section{Agradecimientos}

Quisiera dar las gracias a Sayed Alí, Linda Chapon y la Dra. Auxilio Moreno Onorato por ser mis compañeras inseparables de batalla y a los profesores Eva Alarcón García, Margarita Sánchez Romero, Gonzalo Aranda Jiménez y Gonzalo Ruiz Zapatero por sus comentarios oportunos.

\section{Notas}

3. Concretamente entrevistamos a 70 productores y 50 consumidores, en su mayoría hombres. Las conversaciones establecidas con mujeres, 32 en ámbitos tanto de producción como de consumo, siempre requirieron la presencia de un ente femenino. Para tal fin contamos con la ayuda de Linda Chapon y Auxilio Moreno Onorato, miembros del proyecto arqueológico "Thutmosis III Temple Project".

4. Dato contrastado por medio del uso en la investigación de un pirómetro profesional, modelo ScanTemp 490. Del mismo modo, las referencias de temperatura aportadas en líneas posteriores también han sido corroboradas gracias a la aplicación de esta herramienta.

\section{Bibliografía}

Albero Santacreu, D. (2008): La Calcita como desgrasante añadido en cerámicas arqueológicas prehistóricas: Estado de la Cuestión. I Congreso de Jóvenes en Investigación Arqueológica: Dialogando con la cultura material. JIA 2008 (OrJIA, ed.), Ediciones Cersa, Madrid: 93-100.

Albero Santacreu, D. (2016): Interpreting long-term use of raw materials in pottery production: An holistic perspective. Journal of Archaeological Science: Reports. http://dx.doi.org/10.1016/j.jasrep.2016.04.008

Arnold, D.E. (2006): The Threshold Model for ceramic resources: A refinement. Ceramic studies: papers on the social and cultural significance of ceramics in Europe and Eurasia from prehistoric to historic times (G. Dragos, ed.), Archaeopress, Oxford: 3-9.

Arnold, D.; Bourriau, J. (1993): An Introduction to Ancient Egyptian Pottery. Sonderschriften des Deutschen Archäologischen Instituts Abteilung 17, Mainz.

Bourdieu, P. (1988): La distinción. Criterio y bases sociales del gusto. Taurus, Madrid. 
Bourriau, J.; Nicholson, P.T.; Rose, P. (2000): Pottery. Ancient Egyptian Materials and Technology (P. Nicholson, ed.), Cambridge University Press, Cambridge: 121-147.

Brissaud, P. (1982): Les ateliers de potiers de la région de Louqsor. Institut Français d'Archéologie Orientale du Caire, Cairo.

Calvo Trias, M.; García Rosselló, J. (2012): Tradición técnica y contactos: Un marco de reflexión centrado en la producción cerámica. Rubricatum, 5: 393-401.

Cooper, E. (2000): 10.000 years of Pottery. The British Museum Press, Londres.

David, N.; Kramer, C. (2001): Ethnoarchaeology in action. Cambridge University Press, Cambridge/Nueva York.

Dietler, M.; Herbich, I. (1998): Habitus, techniques, style: an integrated approach to the social understanding of material culture and boundaries. The Archaeology of Social Boundaries (M. Stark, ed.), Smithsonian, Washington: 232-279.

Dobres, M.A. (2000): Technology and social agency. Blackwell, Londres.

Doherty, S.K. (2015): The origins and use of the potter's wheel in ancient Egypt. Archaeopress 7, Oxford.

Duistermaat, K.; Groot, N. (2008): A new ethnoarchaeology documentation project at the Fustat Pottery workshops, Egypt. Leiden Journal of Pottery Studies, 24: 181-186.

Foucault, M. (1992): Vigilar y Castigar. Nacimiento de la prisión. Siglo XXI, Madrid.

García Rosselló, J. (2008): Etnoarqueología de la producción cerámica. Identidad y territorio en los Valles Centrales de Chile. Mayurqa, 32. Monografía.

García Rosselló, J.; Calvo Trías, M. (2013): Making Pots. El modelado de la cerámica a mano y su potencial interpretativo. BAR International Series, 2540, Archaeopress, Oxford.

González-Ruibal, A. (2003): La experiencia del otro. Una introducción a la etnoarqueología. Akal, Madrid.

González-Ruibal, A. (2005): Etnoarqueología de la cerámica en el oeste de Etiopía. Trabajos de Prehistoria, 62(2): 41-66.

González-Ruibal, A. (2011): The Politics of Identity: Ethnicity and the Economy of Power in Iron Age Northern Iberia. Landscape, Ethnicity and Identity in the Archaic Mediterranean Area (G. Cifani, S. Stoddart, eds.), Oxbow books, Oxford: 245-266.

Gosselain, O.P. (2011a): Fine if I do, fine if I don't. Dynamics of technical knowledge in Sub-Saharan Africa. Investigating archaeological cultures (B.W. Roberts, M. Vander Linden, eds.), Springer, Nueva York: 211-227.

Gosselain, O.P. (2011b): Pourquoi le decorer? Quelques observations sur le decor ceramique en Afrique. Azania: Archaeological Research in Africa, 46(1): 3-19.

Hernando Gonzalo, A. (2002): Arqueología de la identidad. Akal, Madrid.

Hernando Gonzalo, A. (2006): Arqueología y Globalización. El problema de la definición del "otro" en la Postmodernidad. Complutum, 17: 221-234.

Hernando Gonzalo, A. (2008): Género y sexo: mujeres, identidad y modernidad. Claves de razón práctica, 188: 64-70.

Hernando Gonzalo, A. (2012): La fantasía de la individualidad. Sobre la construcción sociohistórica del sujeto moderno. Katz. Buenos Aires.

Jamieson, A.; Warfe, A. (2005): Experimental Archaeology and early Pottery Production in the Dakhleh Oasis. Leiden Journal of Pottery Studies, 21: 87-102.

Kawulich, B. (2005): La observación participante como método de recolección de datos. Forum: qualitative social research, Versión online: FQS http://www.qualitative-research.net/fqs/

Lemonnier, P. (1993): Introduction to Technological choices: Transformation in Material Cultures since the Neolithic. Routledge, Londres.

Lemonnier, P. (2012): Mundane Objects: Materiality and Non-verbal Communication. Left Coast Press, Walnut Creek, California.

Lemonnier, P. (en prensa): ¡Hay algo extraño! Objetos estratégicos y comunicación. Etnoarqueología y Experimentación más allá de la analogía (J.J. Padilla Fernández, E. Alarcón García, eds.), Menga, Sevilla.

Michelaki, K.; Braun, G.V.; Hancock R.G.V. (2014): Local clay sources as histories of human-landscape interactions: a ceramic taskscape perspective. Journal of Archaeological Method and Theory, Versión online: DOI 10.1007/s10816-014-9204-0

Nicholson, P.T. (1995): The potters of Deir Mawas, an Ethnoarchaeological Study. Amarna Reports, Vol. VI, Egypt Exploration Society, Londres: 226-238.

Nicholson, P.T. (2009): Pottery Production. UCLA Encyclopedia of Egiptology, Los Ángeles, California: 1-8.

Nicholson, P.T.; Patterson, H.L. (1985): Pottery making in Upper Egypt: an ethnoarchaeological study. World Archaeology, 17: 222-239.

Nicholson, P.T.; Patterson, H.L. (1989): Pottery making in Upper Egypt: a study of pottery firing. World Archaeology, 21: 71-86. 
Nicholson, P.T.; Patterson, H.L. (1991): The Ballas Pottery Project: ethnoarchaeology in Upper Egypt. Ceramic production and distribution: an integrated approach (G.J.I. Bey, C.A. Pool, eds.), Westview Press, Boulder: 25-47.

Padilla Fernández, J.J. (en prensa): Romanization is Coming! The appearance of the potter working class in Iberia at the end of the Second Iron age. Material Chains: Bronze and Iron Age technologies of production in Europe (A. Gorgues, R.B. Salisbury, eds.), Ausonious Editions, Burdeos.

Redmount, C. (2000): Ceramics. The oxford Encyclopedia of Ancient Egypt, vol. 1. (D.B. Redford, ed.), Oxford University Press, Nueva York: 248-256.

Redmount, C. (2003): The Egyptian Modern Pottery Project: Pilot Phase Findings. Egyptian Pottery, Proceedings of the 1990 Pottery Symposium at the University of California (C. Redmount, C. Keller, eds.), ARF, Berkeley: 153-322.

Roux, V.; De Miroschedji, P. (2009): Revisiting the History of the Potter's Wheel in the Southern Levant. Levant, 41(2): 115-173.

Sánchez Elipe, M. (2015): Las comunidades de la Edad del Hierro en África centro-occidental: Cultura material e identidad. Tesis doctoral inédita Universidad Complutense de Madrid.

Velde, B.; Druc, I. (1999): Archaeological Ceramic Materials: Origin and Utilization. Springer, Berlin.

Webmoor, T.; Witmore, C. L. (2008): Things are us! A commentary on human/things relations under the banner of a 'social'archaeology. Norwegian Archaeological Review, 41(1): 53-70.

Wendrich, W. (2013): The Relevance of Ethnoarchaeology: An Egyptian Perspective. Contesting Ethnoarchaologies: Traditions, Theories, Prospects (A. Marciniak, N. Yalman, eds.), Springer, Nueva York: 191-225. 